\title{
Significant Feeding Deterrent of Berberine from Tali kuning(Tinospora dissitiflora Diels) Against Two Subterranean Termites Coptotermes formosanus Shiraki and Reticulitermes speratus Kolbe
}

\author{
Wahyudi, Yoshito Ohtani, and Hideaki Ichiura
}

\begin{abstract}
Antifeedant activities of berberine isolated from the chloroform fraction of Tali kuning (Tinospora dissitiflora Diels) were evaluated against two subterranean termites, Coptotermes formosanus Shiraki and Reticulitermes speratus Kolbe, respectively. The chloroform fraction of methanol extracts of Tali kuning and authentic berberine chloride were used for comparison. Three replicates and levels of concentrations, $12.5,25$, and $50 \mathrm{mg} / \mathrm{ml}$, respectively, were employed. Filtepapers treated with three chemical substances were used to evaluate the mass losses of the filter paper consumed by the termites, and filter papers treated only with $\mathrm{MeOH}$ were used for control. Mass loss (MS), termite mortality (TM) and antifeedant index (AFI) were used to determine the antifeedant variables. The results indicated that regardless of three chemical substances tested, the MS recorded from $C$. formosanus Shiraki were 2.87 times higher than those of $R$. speratus Kolbe, and among three levels concentration, $50 \mathrm{mg} / \mathrm{ml}$ gave the lowest MS (2.13\%). Authentic berberine chloride gave the highest TM (99\%), followed by chloroform fraction (88\%) and berberine (73\%). Interestingly, all antifeedant variables employed in this study gave AFI values less than $20 \%$, indicating significant feeding deterrent activity against two subterranean termites.
\end{abstract}

Keywords: Berberine, Tali kuning, subterranean termites, significant feeding deterrent activity.

\section{Introduction}

Ecologically, termites play a key role in decomposition of lignocellulosic materials for bio-recycling and promoting carbon turn over into the environment. However, their actions on bio-deterioration of woods, wood associated products, and other lignocellulosic materials are a serious problem for wood utilization, having economical and environmental impacts (Silva et al. 2009). Economic damages caused by termite annually are estimated at about US $\$ 50$ billion worldwide and U.S alone spent at US $\$ 11$ billion for controlling termite in 1995 (Korb 2007). Two subterranean termite species (Isoptera: Rhinotermitidae), Coptotermes formosanus Shiraki and Reticulitermes speratus Kolbe, respectively, are the major of economic importance in Japan (Nakayama et al. 2005), and one of the most destructive pests in the U.S (Fokialakis et al. 2007). Toxicity and repellency are two important factors used to determine the efficacy of antitermitic substances for subterranean termite invasion (Maistrello et al. 2001). Antitermitic compounds having non-repellent activity with highly toxic substances that kill termite rapidly or highly repellant substance are strongly recommended (Su et al. 2001).

Considerably growing concerns on the toxicity impacts of synthetic termiticidal insecticides on human and environmental health have led to the search of alternative insecticides possessing minimal risks (Fokialakis et al. 2007). The searches for antitermitic substances from naturally occurring compounds are increasing rapidly and tremendous efforts have been achieved and reported worldwide. For example, essential oils from leaves of
Eucalyptus camaldulensis (volatile compounds) obtained from Thailand had shown anti-termite activities against the subterranean termite Coptotermes formosanus Shiraki (Siramon et al. 2008). Several naturally occurring substances classified as non-volatile compounds, such as wood extractives (Santana et al. 2010), alkaloids (Kawaguchi et al. 1989), flavonoids (Ohmura et al. 2000; Norimoto et al. 2006; Sekinne et al. 2009;), thiophenes (Fokialakis et al. 2007), terpenoids (Seo et al. 2009), and quinones (Lajide et al. 1995) have also been reported for their antitermitic activities.

Following the isolation and structural elucidation of berberine from the chloroform fraction of Tali kuning (Wahyudi et al. 2010, 2011), antifeedant activities of berberine and chloroform fraction from Tali kuning were evaluated against two subterranean termites, C. formosanus Shiraki and $R$. speratus Kolbe. It is due to the facts that naturally occurring Tali kuning ( $T$. dissitiflora Diels) lies down on the forest floor mixing with the decomposed litters, and probably has anti-termite substances.

\section{Materials and Methods}

The source and field for the collection of Tali kuning ( $T$. dissitiflora Diels), specimen identification, and sample preparation of stem wood powders used in this study were similar to those reported in the previous papers (Wahyudi et al. 2010, 2011). Procedures used to separate and isolate berberine were also similar to those reported in the previous references. Authentic berberine chloride was purchased from Wako Ltd., Osaka, Japan. Two subterranean termites, $C$. formosanus Shiraki and $R$. speratus Kolbe were collected 
from the field, Kochi prefecture, Japan on May and November 2010. Termites were reared at incubator (Sanyo MIR 123, Japan) at $27^{\circ} \mathrm{C}$, fed with filter papers, and regularly added with distilled water until used.

\section{Antifeedant Tests}

Contact method was used to evaluate antifeedant activities. Round filter papers (Whatman No $3,3 \mathrm{~cm}$ in diameter) were prepared using rotary cutter and the initial weight of the original filter paper was determined with analytical balance. Each chemical substance, berberine, chloroform fraction, and berberine chloride standard, respectively, quantity of $2.5,5$, and $10 \mathrm{mg}$, respectively, were weighted, and transferred to the labeled microtubes. Amount of $200 \mu \mathrm{L}$ of $\mathrm{MeOH}$ was added to the filled microtubes to obtain an equal concentration of 12.5, 25, and $50 \mathrm{mg} / \mathrm{ml}$. The $50 \mu \mathrm{L}$ syringe (Hamilton Co., USA) was used to transfer each chemical solution to the filter papers. The treated filter papers were exposed at room temperature overnight to release $\mathrm{MeOH}$. The treated filter papers were re-weighted to determine the gained weight of the filter papers with chemical substances. Two grams of quartz sand (average particle size: $750 \mu \mathrm{m}$, Wako pure Ltd., Osaka, Japan) was homogenously layered on the bottom of petri plates ( $6 \mathrm{~cm}$ in diameter and $1 \mathrm{~cm}$ height), and moistured by addition of distilled water occasionally. The treated filter papers were placed on the center of petri plates. Fifty termite workers above $3^{\text {rd }}$ instar were supplied to each petri plates, and covered with the petri plate covers. These petri plates were placed in dark condition in the incubator at $27^{\circ} \mathrm{C}$ and monitored daily for 14 days. Three replicates were employed to all antifeedant variables. The filter papers treated with $\mathrm{MeOH}$ only were used as control.

\section{Antifeedant Variables}

Antifeedant activities were evaluated using the variables used by Sekinne et al. (2009) consisting of mass loss (MS) and termite mortality (TM), respectively, and both were expressed in percentage (\%). The MSs were the eight losses of the filter papers after testing. The TMs were the percent values (number of dead termites/ number of the initial termites $x$ 100). Antifeedant index (AFI) was used to evaluate the feeding preferences of the termites. AFI can be calculated as follows: $T /(C+T) \times 100$, where $T$ is $\%$ weight loss of treated filter papers consumed by termite and $\mathrm{C}$ is the control ones (Lajide et al. 1995). In addition, AFI values less than $20 \%$ indicates significant feeding-deterrent, $50 \%$ is equal to control, and greater than $80 \%$ denotes strong feeding stimulation. The concentration of chemical substances having $50 \%$ antifeedant activity compared with a control was determined using the method introduced by Zheng et al. (2008) with a few modifications and 50\% antifeedant index $\left(\mathrm{AFI}_{50}\right)$ was calculated with probit analysis using Statplusmac statistical program (Analyst soft, Canada).

\section{Results and Discussion}

\section{Mass Loss (MS)}

Coptotermes formosanus Shiraki showed higher means for MSs, $62.2 \%$ for the control and $5.82 \%$ for the treated filter papers. On the other hands, $R$. speratus showed MSs mean of 35.7 and $2.03 \%$ for the control and treated filter papers, respectively. There were statistically highly significances (one-way ANOVA, $p=0.0001$ ). Further analyses were conducted using least significant differences (LSD), Fisher's LSD post-hoc test (Table1), indicated that MSs of $R$. speratus Kolbe were more homogenous (a-b) than those of $C$. formosanus Shiraki (a, b, $c$, and d). Among three levels of concentration, it was indicated that the lowest MS $(2.13 \%)$ was recorded from the highest concentration (50 mg/ml), followed by 6.0 , and $3.70 \%$ from 25 and 12.5 $\mathrm{mg} / \mathrm{ml}$, respectively (significant, one-way ANOVA, $\mathrm{p}=0.002$ ). Fisher's LSD post-hoc test (Table 1) also highlights that the highest concentration from $R$. speratus Kolbe gave the similar levels of MS significance (a), while $C$. formosanus Shiraki provided two levels of MS significance (a and ab). On the other hand, among three chemical species, there was no significant effect on the MSs against two subterranean termites.

Table 1. Mass loss (MS) and antifeedant index (AFI) - Antifeedant activities of berberine from the chloroform fraction of Tali Kuning ( $T$. dissitiflora Diels) against two subterranean termites.

\begin{tabular}{|c|c|c|c|c|c|c|c|}
\hline & \multirow[b]{2}{*}{$\begin{array}{l}\text { Concentration } \\
(\mathrm{mg} / \mathrm{ml})\end{array}$} & \multicolumn{3}{|c|}{ Coptotermes formosanus Shiraki } & \multicolumn{3}{|c|}{ Reticulitermes speratus Kolbe } \\
\hline & & Berberine & $\mathrm{CHCl}_{3} \mathrm{Frac}$ & Berberine chloride & Berberine & $\mathrm{CHCl}_{3} \mathrm{Frac}$ & $\begin{array}{l}\text { Berberine } \\
\text { chloride }\end{array}$ \\
\hline \multirow{4}{*}{ MS $(\%)$} & 12.5 & $11.5 \pm 3.7^{d}$ & $10.4 \pm 2.4^{d}$ & $7.2 \pm 1.2 \mathrm{bcd}$ & $2.7 \pm 0.2^{a b}$ & $2.8 \pm 0.5^{a b}$ & $1.2 \pm 0.3^{a}$ \\
\hline & 25 & $8.2 \pm 1.3^{\mathrm{cd}}$ & $5.1 \pm 1.4 \mathrm{abc}$ & $2.6 \pm 1.2 \mathrm{ab}$ & $2.1 \pm 0.9 a$ & $2.1 \pm 0.6^{a}$ & $2.0 \pm 0.7^{a}$ \\
\hline & 50 & $2.4 \pm 0.6^{a}$ & $1.7 \pm 2.1^{a}$ & $3.3 \pm 1.2 \mathrm{ab}$ & $2.2 \pm 0.3^{a}$ & $2.0 \pm 0.8^{a}$ & $1.2 \pm 0.3^{a}$ \\
\hline & 0 (control) & & 62.2 & & & 35.7 & \\
\hline \multirow{3}{*}{ AFI (\%) } & 12.5 & $15.4 \pm 2.9^{d}$ & $14.3 \pm 2.9^{d}$ & $10.3 \pm 1.5^{\mathrm{bcd}}$ & $7.1 \pm 0.4 \mathrm{abc}$ & $7.2 \pm 1.2 \mathrm{abc}$ & $3.2 \pm 0.9^{a}$ \\
\hline & 25 & $11.6 \pm 1.7^{\mathrm{cd}}$ & $7.5 \pm 1.9 a b c$ & $4.0 \pm 1.7 \mathrm{ab}$ & $7.2 \pm 2.1 \mathrm{abc}$ & $5.5 \pm 1.5 \mathrm{abc}$ & $5.2 \pm 1.7 \mathrm{ab}$ \\
\hline & 50 & $3.7 \pm 0.9 a$ & $2.7 \pm 3.2^{a}$ & $4.9 \pm 1.7 \mathrm{ab}$ & $3.2 \pm 0.8^{a}$ & $5.2 \pm 1.9 \mathrm{ab}$ & $3.2 \pm 0.6$ \\
\hline
\end{tabular}


Significant differences in the MSs between two subterranean termite species indicated that both species showed different feeding preferences, and it was presumably that $R$. speratus Kolbe had higher feeding deterrence than $C$. formosanus Shiraki, since $C$. formosanus Shiraki consumed more filter papers than $R$. speratus Kolbe. Nakayama et al. (2004) reported that $C$. formosanus Shiraki had higher wood consumption rates $(0.12 \sim 0.27 \mathrm{mg} /$ day/worker) than those of $R$. speratus Kolbe (0.05 0.07 mg/day/worker), when these two subterranean termites were tested at temperature $\left({ }^{\circ} \mathrm{C}\right)$ and humidity (\%) ranging from $25 \sim 35^{\circ} \mathrm{C}$ and $50-90 \%$, respectively. Also, it was highlighted that berberine and chloroform fraction of Tali kuning demonstrated antifeedant activity because the filter papers treated with these chemical substances were lesspreferable or distasteful for the termite feeding, compared to the control filter papers.

\section{Termite Mortality (TM)}

Two subterranean termites had similar TM values, 84.4 and $84.7 \%$ for $C$. formosanus and $R$. speratus, respectively, and they were not significant (one-way ANOVA, $p=0.96$ ). However, three chemical substances showed statistically significant effects on TM (one-way ANOVA $p=0.03$ ), where the highest TM $(93 \%)$ was obtained from authentic berberine chloride, followed by chloroform fraction $(88 \%)$ and berberine $(73 \%)$. The effects of three levels of concentration on TM were also highly significant $(p=0.00001)$, where $99 \%$ of TMs were obtained from the highest concentration $(50 \mathrm{mg} / \mathrm{ml})$ for both subterranean termites. When the concentration of $50 \mathrm{mg} / \mathrm{ml}$ was reduced to $25,12.5 \mathrm{mg} / \mathrm{ml}$, the TMs for both subterranean termites were still higher (82 and $73 \%$, for 25 and $12.5 \mathrm{mg} / \mathrm{ml}$, respectively) than TM of the control. Importantly, TMs obtained from all experiments using chemical substances were higher than those from the controls.

Different TM rates counted at 3,7 and 14 days are showed in Figure 1 (a, b, and c) for $C$. formosanus Shiraki and $2(\mathrm{a}, \mathrm{b}$, and $\mathrm{c})$ for $R$. speratus Kolbe, respectively. Regardless of levels of concentration and chemical substances, Figures (1 and 2) indicate that from $1 \sim 7$ days, the numbers of dead termites of $C$. formosanus Shiraki were higher than those of $R$. speratus Kolbe. For example, by day 7 at $50 \mathrm{mg} / \mathrm{ml}$ concentration more than $90 \%$ of $C$. formosanus Shiraki were died, but less than $40 \%$ of $R$. speratus Kolbe were died. Surprisingly, by day 14 approximately $99 \%$ of both subterranean termites were died at concentration of $50 \mathrm{mg} / \mathrm{ml}$.

Termite mortality of $R$. speratus Kolbe obtained from this study was higher than that reported by Kawaguchi et al. (1989). They reported that employing berberine chloride gave TMs of $10,36.7$ and $70 \%$ at concentration of 100 $\mu \mathrm{g} /$ disc ( $8 \mathrm{~mm}$ diameter of filter paper), and TM of 20, 43.3, and $83.3 \%$ at concentration of $300 \mu \mathrm{g} / \mathrm{disc}$ recorded at 10 , 20 , and 30 days, respectively. Higher TM in this study is probably due to higher concentration employed.

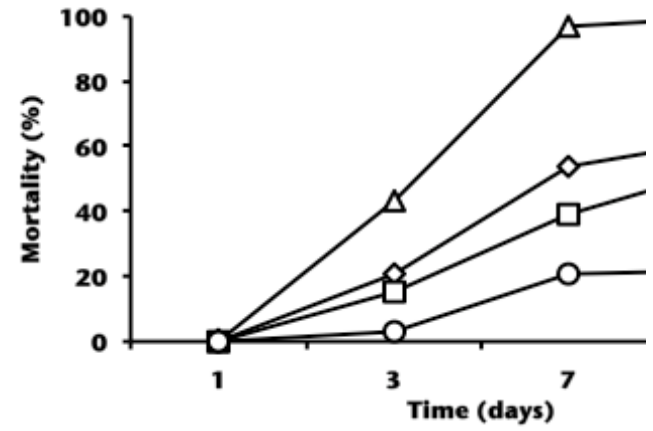

(a)

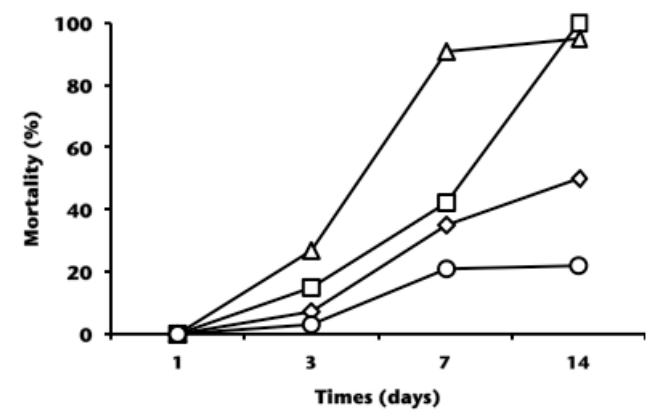

(b)

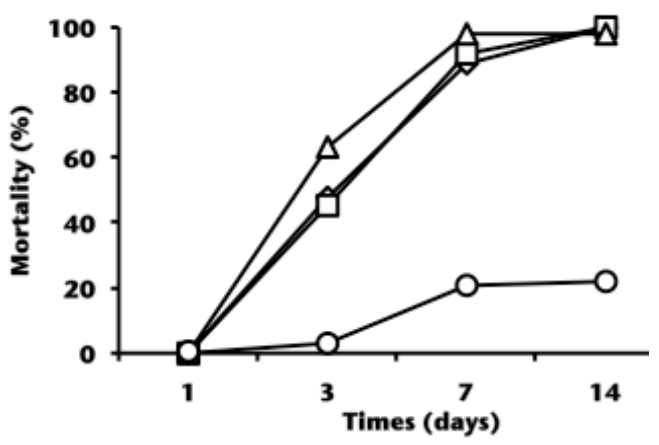

(c)

Figure 1. Termite mortality rates for $C$. formosanus Shiraki by berberine (a), chloroform fraction (b) and authentic berberine chloride (c). Concentrations were $(\diamond) 12.5 \mathrm{mg} / \mathrm{ml}$, () $25 \mathrm{mg} / \mathrm{ml}$, and $(\Delta) 50$ $\mathrm{mg} / \mathrm{ml}$. MeOH was used as control (o). Each point represents the means of three replications. 


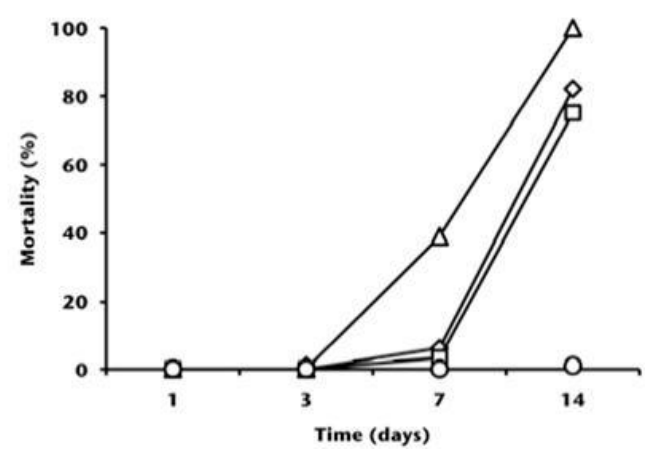

(a)

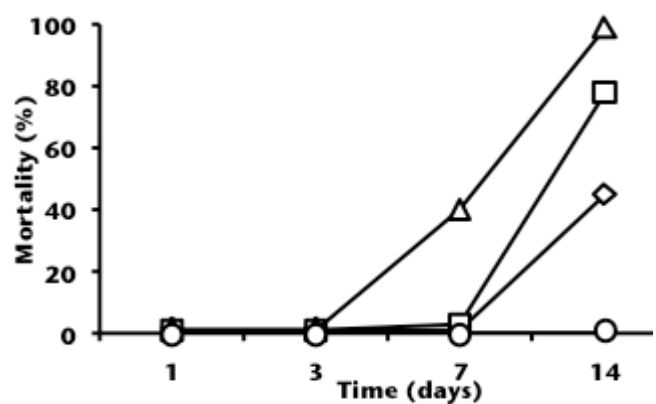

(b)

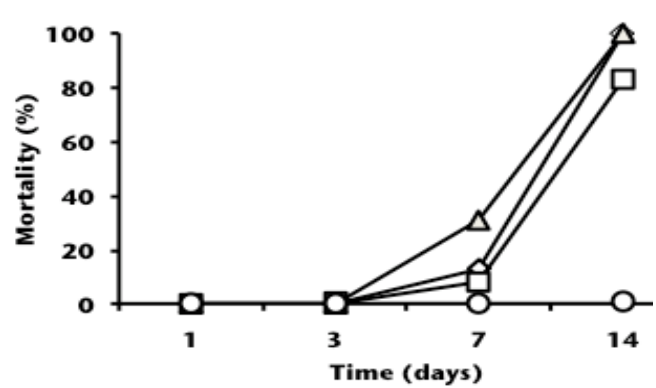

(c)

Figure 2. Termite mortality rates for $R$. speratus Kolbe by berberine (a), chloroform fraction (b) and authentic berberine chloride (c). Concentrations were $(\diamond)$ 12.5, () 25 , and $(\Delta) 50 \mathrm{mg} / \mathrm{ml}$. MeOH was used as control (O). Each point represents the means of three replications.

\section{Antifeedant Index (AFI)}

Reticulitermes speratus Kolbe had lower AFI (5.3\%) than C. formosanus Shiraki (8.3\%), and statistically both were highly significant (one-way ANOVA, $p=0.007$ ). In terms of concentration levels, the lowest AFI (4.35\%) was obtained from $50 \mathrm{mg} / \mathrm{ml}$, followed by $25 \mathrm{mg} / \mathrm{ml}(6.6 \%)$, while $12.5 \mathrm{mg} / \mathrm{ml}$ gave the highest AFI (9.6\%) and they were also highly significant (one-way ANOVA $p=0.0002$ ). AFIs obtained from three chemical substances were comparable one another (not significant, $p=0.076$ ), where berberine chloride had the lowest $(5.2 \%)$, followed by chloroform fraction $(7.04 \%)$ and berberine $(8.2 \%)$. Interestingly, the
AFI values obtained from all experiments with chemical substances in this study were less than $20 \%$. Therefore, it was concluded that the compounds used in this study had significant feeding deterrent activity against $C$. formosanus Shiraki and $R$. speratus Kolbe, respectively.

AFIs in this study were comparable to those reported by Norimoto et al. (2006), where three pterocarpans and two pterocarpols from the dicloromethane extract of the heartwood of Pterocarpus macrocarpus Kruz had antifeedant activity against subterranean termite $R$. speratus Kolbe by using filter papers (6 $\mathrm{mm}$ in diameter) at concentration of $50 \mu \mathrm{g} /$ disk. Three pterocarpans [(-)homopterocarpin, (-)-pterocarpin, and (-)hydroxyhomopterocarpin] gave AFIs of $5.3,6.9$, and $9.6 \%$, respectively, whereas the sequiterpene alcohol and $(+)$ pterocarpol had AFIs of 7.1 and $41.8 \%$, respectively.

The $50 \%$ antifeedant indices $\left(\mathrm{AFI}_{50}\right)$ based on the control against C. formosanus Shiraki were 4.61, 4.13, and $0.61 \mathrm{mg} / \mathrm{ml}$, for chloroform fraction, berberine and authentic berberine chloride, respectively. However, $\mathrm{AFI}_{50}$ for $R$. speratus Kolbe was not able to be gained because the MS values obtained from the control were less than $50 \%$.

\section{Conclusions}

It can be summarized that berberine isolated from the chloroform fraction of Tali kuning (Tinospora dissitiflora Diels) showed significant feeding deterrent activity against two subterranean termites, and among the experimental variables, concentration levels mostly affected the antifeedant activity, in which $99 \%$ of TM could be achieved at $50 \mathrm{mg} / \mathrm{ml}$ concentration by day 14 for both subterranean termites. Significant differences in mass losses, termite mortality rates, and antifeedant indices between $C$. formosanus Shiraki and $R$. speratus Kolbe may influence the feeding behaviors and distributions of these two subterranean termite species in the nature.

\section{References}

Fokialakis, N.; W.L.A. Osbrink; L.K. Mamonov; N.G. Gemejieve; A.B. Mims; A.L. Skaltsounis; A.R. Lax; C.L. Cantrell. 2006. Antifeedant and Toxicity effect of Thiophenes from Four Echinops Species Against the Formosan Subterranean Termite, Coptotermes formosanus. Pest Management Science 62: 832-838.

Kawaguchi. H.; M. Kim; M. Ishida; Y. Ahn; T. Yamamoto; R. Yamaoka; M. Kozuka; K. Goto; S. Takahashi. 1989. Several Antifeedants from Phellodendron amurense Against Reticulitermes speratus. Agriculture Biology and Chemistry 53(10): 2635-2640.

Korb, J. 2007. Termite. Current Biology 17: 995-999.

Lajide, L.; P. Escoubas; J. Mizutani. 1995. Termite Antifeedant Activity in Xylopia aethiopica. Phytochemistry 40(4): 1105-1112.

Maistrello, L.; G. Henderson; R.A. Laine. 2001. Efficacy of 
Vetiver Oil and Nootkatone as Soil Barrier Against Formosan Subterranean Termite (Isoptera: Rhinotermitidae). Journal of Economist Entomology 94: 1532-1537.

Nakayama, T.; T. Yoshimura; Y. Imamura. 2004. The Optimum Temperature-humidity Combination for Feeding Activities of Japanese Subterranean Termites. Journal of Wood Science 50: 530-534.

Nakayama, T.; T. Yoshimura; Y. Imamura. 2005. Feeding Activities of Coptotermes formosanus and Reticulitermes speratus (Kolbe) as Affected by Moisture Content of Wood. Journal of Wood Science 51: 60-65.

Norimoto, M.; H. Fukumoto; M. Hiratani; W. Chavasiri; K. Komai. 2006. Insect Antifeedants, Pterocarpans and Pterocarpol, in Heartwood of Pterocaparpus macrocarpus Kruz. Bioscience Biotechnology and Biochemistry 70(8): 1864-1868.

Ohmura, W.; S. Doi; M. Aoyama; S. Ohara. 2000. Antifeedant Activity of Flavonoids and Related Compounds Against the Subterranean Termite Coptotermes formosanus Shiraki. Journal of Wood Science 46: 149-153.

Santana, A.L.B.D.; C.A. Maranhao; J.C. Santos; F.M. Cunha; G.M. Conceicao; L.W. Bieber; M.S., Nascimento. 2010. Antitermitic Activity of Extractives from Brazilian Hardwoods Extractives Against Nasutitermes corniger. International Biodeterioration \& Biodegradation 64: 7-12.

Sekinne, N.; T. Ashitani; T. Murayama; S. Shibutani; S. Hattori; K. Takahashi. 2009. Bioactivity of Latifolin and Its Derivative Against Termite and Fungi. Journal of Agriculture and Food Chemistry 57: 5707-5712.

Seo, S.; J. Kim; S. Lee; C. Shin; S. Shin; I. Park. 2009. Fumigant Antitermitic Activity of Plant Essential Oils and Components from Ajowan (Trachyspermum ammi), Allspice (Pinnatadioica), Caraway (Carum carvi), Dill (Anethum graveolens), Geranium (Pelargonium graveolens), and Litsea (Litsea cubeba) Oils Against Japanese Termite (Reticultermes speratus Kolbe). Journal of Agriculture and Food Chemistry 56: 65956602.

Silva, M.D.C.; S.D.A. Napoleao; T.H. Gomes; F.S. Santos; N.D.L. Albuquerque; H.S. Xavier; P.M.G. Paiva; M.T.S. Correia; L.C.B.B. Coelho. 2009. Purified Cladonia verticillaris Lichen Lectin: Insecticidal Activity on
Nasutitermes corniger (Isoptera: Termidae). International Biodeterioration \& Biodegradation 63: 334-340.

Siramon, P.; Y. Ohtani; H. Uchiura. 2008. Biological Performances of Eucalyptus camaldulensis Leaf Oils from Thailand Against the Subterranean Termite Coptotermes formosanus Shiraki. Journal of Wood Science 55: 41-46.

Su, N.Y.; M. Tamashiro; J.R. Yates; M.I. Harverty. 2001. Effect of Behavior on the Evaluation of Insecticides for Prevention of Remedial Control of Formosanus Subterranean Termite. Journal of Economist Entomology 75:188-193.

Wahyudi, Y. Ohtani; H. Ichiura. 2010. Berberine, A Main Secondary Metabolite Isolated from Tali kuning (Tinospora dissitiflora Diels), An Indigenous Medicinal Plant from Manokwari, Papua, Indonesia. Abstract of the $22^{\text {nd }}$ Meeting of the Chugoku-Shikoku Branch of the Japan Wood Research Society: 14-15. ISSN 09193960.

Wahyudi; Y. Ohtani; H. Ichiura. 2011. Strong Antifeedancy of Nerberine in Tali Kuning (Tinosporadissitiflora Diels) Against Japanese Subterranean Termite Reticulitermes speratus Kolbe. Journal of Forest Biomass Utilization (in press).

Zheng, H.; F.C. Zhou; D. Xu; M. Afzal; M.H. Bashir; S. Ali; S. Freed. 2008. Antifeedant Activities of Secondary Metabolites from Ajuga nipponensis Against Plutella xylostella. Pakistan Journal Botany 40 (5): 1983-1992.

Wahyudi

Department of Wood Sience and Forest Products

Faculty of Forestry, the State University of Papua

Manokwari, West Papua, Indonesia

Tel : : 62-986-211065

Fax : : 62-986-211065, 211455

Email : wahyoedhi@lycos.com

Yoshito Ohtani and Hideaki Ichiura

Department of Forest Science, Faculty of Agriculture

Kochi University

Nankoku, Kochi, 783-802 Japan.

Tel : : +81-88 8645143

Fax : : +81-88 8645143

Email : ohtani@kochi-u.ac.jp. 